\title{
MRI in acute muscle tears in athletes: can quantitative T2 and DTI predict return to play better than visual assessment?
}

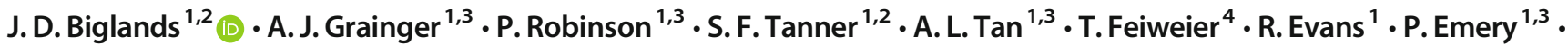 \\ P. O'Connor ${ }^{1,3}$
}

Received: 9 March 2020 / Revised: 14 April 2020 / Accepted: 3 June 2020 / Published online: 15 July 2020

(C) The Author(s) 2020

\begin{abstract}
Objectives To assess the ability of quantitative T2, diffusion tensor imaging (DTI) and radiologist's scores to detect muscle changes following acute muscle tear in soccer and rugby players. To assess the ability of these parameters to predict return to play times.

Methods In this prospective, longitudinal study, 13 male athletes (age 19 to 34 years; mean 25 years) underwent MRI within 1 week of suffering acute muscle tear. Imaging included measurements of T2 and DTI parameters. Images were also assessed using modified Peetrons and British athletics muscle injury classification (BAMIC) scores. Participants returned for a second scan within 1 week of being determined fit to return to play. MRI measurements were compared between visits. Pearson's correlation between visit 1 measurements and return to play times was assessed.

Results There were significant differences between visits in BAMIC scores $(Z=-2.088 ; p=0.037)$, modified Peetrons $(Z=-$ 2.530; $p=0.011)$ and quantitative MRI measurements; T2, $13.12 \mathrm{~ms} \mathrm{(95 \%} \mathrm{CI,} 4.82 \mathrm{~ms}, 21.42 \mathrm{~ms} ; p=0.01)$; mean diffusivity $(0.22(0.04,0.39) ; p=0.02)$ and fractional anisotropy $(0.07(0.01,0.14) ; p=0.03)$. BAMIC scores showed a significant correlation with return to play time $\left(R_{\mathrm{S}}=0.64 ; p=0.02\right)$, but modified Peetrons scores and quantitative parameters did not.

Conclusions T2 and DTI measurements in muscle can detect changes due to healing following muscle tear. Although BAMIC scores correlated well with return to play times, in this small study, quantitative MRI values did not, suggesting that T2 and DTI measurements are inferior predictors of return to play time compared with visual scoring.

Key Points

- Muscle changes following acute muscle tear can be measured using T2 and diffusion measurements on MRI.

- Measurements of T2 and diffusion using MRI are not as good as a radiologist's visual report at predicting return to play time after acute muscle tear.
\end{abstract}

Keywords Skeletal muscles $\cdot$ Diffusion tensor MRI $\cdot$ Multi-parametric MRI $\cdot$ Muscle tear

Abbreviations

BAMIC British athletics muscle injury classification

DTI Diffusion tensor imaging

J. D. Biglands

j.biglands@nhs.net

1 NIHR Leeds Biomedical Research Centre, Leeds Teaching Hospitals NHS Trust, Leeds, UK

2 Medical Physics and Engineering, Leeds Teaching Hospitals NHS Trust, Leeds, UK

3 Leeds Institute of Rheumatic and Musculoskeletal Medicine, Chapel Allerton Hospital, University of Leeds, Leeds, UK

4 Siemens Healthcare GmbH, Erlangen, Germany

$\begin{array}{ll}\text { FA } & \text { Fractional anisotropy } \\ \text { MD } & \text { Mean diffusivity } \\ \text { MRI } & \text { Magnetic resonance imaging } \\ \text { ROI } & \text { Region of interest } \\ \text { SPAIR } & \text { Spectral adiabatic inversion recovery } \\ \text { STEAM } & \text { Stimulated echo acquisition mode }\end{array}$

\section{Introduction}

Acute muscle tears are common in athletes and have a particularly high prevalence in the lower limb [1]. These injuries are responsible for a significant loss of time spent in competition, with pressure on medical teams to return athletes to 
competition rapidly [2]. However, premature return may result in recurrent injury and a longer period of convalescence [3]. Subsequently, injury diagnosis and prediction of time to return to play are active areas of research, including injury classification using magnetic resonance imaging (MRI) [2-5].

The modified Peetrons $[6,7]$ and British athletics muscle injury classification (BAMIC) $[8,9]$ scores are the most commonly used MRI muscle injury grading techniques. They are based on the site and size of injury within the muscle and the morphological features of the tear. Numerous studies have investigated the ability of standard MRI to predict return to play times, with the majority finding no association [6, 10-16]. However, the ability of quantitative MRI to predict return to play times has not been assessed.

Quantitative MRI measurements may be useful as an objective assessment of muscle tears. T2 measurements have been shown to be able to detect subtle muscle changes due to disease $[17,18]$ and exercise $[19,20]$ and can also show muscle degeneration and regeneration after femoral artery ligation in mice [21]. DTI parameters also have potential as a quantitative assessment of muscle, being particularly responsive to the size and directionality of water diffusivity in injured muscle [22]. STEAM-DTI measurements have been shown to be able to detect differences between muscle tear and healthy muscle in the same patient [23] and quantitative MRI has been shown to be useful in cross-sectional studies [21-23]. However, the ability of quantitative MRI to detect longitudinal changes due to healing after acute muscle tear has not yet been assessed.

The aims of this longitudinal, observational study were to assess the ability of quantitative T2 and STEAM-DTI parameters to detect muscle changes following acute muscle tear and to assess the correlation between these parameters and return to play times. We tested the hypotheses that there was no difference in quantitative MRI measurements at the time of tear and at time of returning to play, and that there was no correlation between these measurements and return to play time.

\section{Methods}

\section{Participants}

Consecutive referrals, from professional soccer and rugby clubs, for clinically indicated MR examination of a muscle injury were recruited into this study. Participants gave written, informed consent to take part with approval of the National Research Ethics Service (17-EM-0079). The study was conducted according to the Declaration of Helsinki. Sample size was based on published rules of thumb for estimating parameters for powering future clinical trials [24]. Inclusion criteria were clinical evidence of a muscle tear in the lower limb with at least 2 of the following criteria present: history of pain in a muscle group commencing during sporting activity, pain on walking $24 \mathrm{~h}$ after injury, local tenderness to palpation of the affected muscle, reduced muscle power and range of movement on specific muscle testing (i.e., 90-90 test for the hamstrings).

Exclusion criteria were contraindications for MRI, reinjury on return to play (which was considered a premature return to play) or non-attendance at the follow-up scan. Participants were not excluded based on age, comorbidities or previous muscle injury. The recruitment period extended from 11 March 2016 to 18 April 2017.

\section{MR imaging}

Initial MR imaging was performed 0-7 days following muscle injury (visit 1). The sports teams were provided with a report of the MR scan, which included a description of the site and size of the muscle injury in keeping with the ethical requirements of the study, but were blinded to tear study scores on MRI. Follow-up imaging was performed 0-7 days after the participant was classed as fit to return to play (visit 2). Criteria for the return to play decision-making included asymptomatic completion of a rehabilitation program and a subjective clinical assessment by the sports medicine team. Return to play time was recorded as the time from injury until the participant returned to full, unrestricted training.

Image acquisition was performed using a previously described protocol [25]. MR data were acquired using a MAGNETOM Verio 3-T MR scanner (Siemens Healthcare) using two, small, four-channel flex coils wrapped around the injured leg. The scan parameters for the imaging are given in Table 1. The fields of view for all imaging sequences were fixed at $300 \times 300 \mathrm{~mm}^{2}$. The musculoskeletal radiologist identified the slice position of the centre of the muscle tear site on the short tau inversion recovery (STIR) volume (Table 1). The $\mathrm{T} 2$ and diffusion images were then aligned with this slice position.

Diffusion-weighted images were acquired using a STEAM prototype sequence. To measure $\mathrm{T} 2$, a multi-echo spin-echo (MESE) sequence was used. A volume-interpolated breathhold examination (VIBE), 2-point Dixon sequence, TR $11 \mathrm{~ms}$, TE $2.45 \mathrm{~ms}$ and $3.675 \mathrm{~ms}$, flip angle $15^{\circ}$, duration $94 \mathrm{~s}$, was also acquired. These Dixon images were used to obtain signal-weighted fat-fraction estimates to check region of interest (ROI) placement for subcutaneous and fascial fat.

\section{Image analysis}

Modified Peetrons [7] and BAMIC [9] semi-quantitative muscle tear scoring was performed on anonymised STIR axial image volumes by a consultant musculoskeletal radiologist (P.R.) who was blinded to the visit ordering. In order to assess 
Table 1 MRI scan parameters for T1-weighted, T2 measurements and STEAM diffusion scans

\begin{tabular}{llll}
\hline & T1 weighted & T2 & Diffusion \\
\hline Imaging sequence & Turbo spin-echo (TSE) & Multi-echo, spin-echo (MESE) & STEAM-EPI \\
TR: repetition time $(\mathrm{ms})$ & 697 & 1500 & 6300 \\
TE: echo time(s) $(\mathrm{ms})$ & 9.1 & $9.6: 9.4: 153.6$ (16 echos) & 42.2 \\
Field of view $(\mathrm{mm})$ & $300 \times 300$ & $300 \times 300$ & $300 \times 300$ \\
Slice thickness $(\mathrm{mm})$ & 5 & 5 & 5 \\
Fat suppression & STIR & SPAIR & SPAIR \\
Acquisition matrix & $256 \times 256$ & $256 \times 256$ & $256 \times 256$ \\
Number of slices & 60 & 5 & 5 \\
Number of averages & 1 & 1 & 8 \\
Receiver bandwidth $(\mathrm{Hz} /$ pixel) & 222 & 510 & 1502 \\
Flip angle $\left({ }^{\circ}\right)$ & 90 & 15 & - \\
GRAPPA & - & - & 2 \\
$b$ values $\left(\mathrm{s} / \mathrm{mm}^{2}\right)$ & - & - & 0,500 \\
Directions & - & - & 6 \\
Mixing time $(\mathrm{Tm})(\mathrm{ms})$ & - & - & 980 \\
Diffusion time $(\Delta)(\mathrm{ms})$ & - & - & 1000 \\
Acquisition time $(\mathrm{min}: \mathrm{s})$ & $2: 19$ & $2: 05$ & $6: 12$ \\
\hline
\end{tabular}

correlations, BAMIC scores were converted to an ordinal scale. ROIs defining the tear site, oedematous muscle, normal muscle and any haematoma were drawn on a single slice at both visit 1 and visit 2 images by a separate consultant musculoskeletal radiologist (P.J.O.C.). Scoring and ROI drawing were performed by two different radiologists (both with over 20 years of experience of muscle tear imaging) to avoid memory bias from the contouring stage.

To make direct comparisons between visits, ROIs drawn on the STIR images were aligned between visits using image registration. Movement between different acquisitions within the visit was also corrected for. The image registration process is illustrated in Fig. 1 and is described as follows:

1. An initial bounding box was defined around the leg to exclude the contralateral leg using threshold analysis.

2. For alignment between visits, two-dimensional affine image registration was applied to the STIR images at the tear site slice. The optimisation of the transform parameters was achieved with a regular-step gradient descent optimiser [26] and Mattes' implementation of the mutual information image similarity metric [27].

3. The image transform obtained in step 2 was then applied to the remaining visit 2 images, i.e. the DTI maps and TSE images.

4. For within-visit alignment, a rigid registration was used. As patient movement within a single scanning session was small, it was expected that rigid registration would be adequate for this step.
Registration was evaluated on a case-by-case basis by two consultant musculoskeletal radiologists (P.J.O.C., A.G.) based on whether the ROIs visually aligned with the tear site on the target visit images. In some cases, haematoma (detected at visit 1 in close proximity to subcutaneous fat) had completely resolved by visit 2 , which could result in subcutaneous fat being classified as haematoma in visit 2. Therefore, visit 2 ROIs that had a signal-weighted fat-fraction of over $20 \%$ were assumed to contain signal outside the muscle and were excluded from the study.

To generate $\mathrm{T} 2$ values, the signal intensity versus echo time decay curves from each ROI were fitted with a monoexponential function including a constant term to account for the noise floor. The earliest time point in the echo train was excluded from the fit [28]. Mean diffusivity (MD), fractional anisotropy (FA) and diffusion eigenvalue $\left(\lambda_{1}, \lambda_{2}, \lambda_{3}\right)$ maps were generated using the scanner vendor's software.

Two comparative studies to assess healing were made. In the first, quantitative MRI parameters from ROIs drawn at visit 1 were compared between visits. These changes are important to understand because the visit 1 measurements are the basis for predicting return to play time. However, this comparison reflects healing changes both within the tear site and due to reduction of the size of the tear. Therefore, to assess changes within the tear site independent of tear size reduction, a second comparison was performed. Here, quantitative MRI parameters from tear site ROIs drawn in the remaining tear at visit 2 were compared with the values at visit 1 at the same position. Because both ROIs in this comparison lay within the tear site, these 
Visit 1

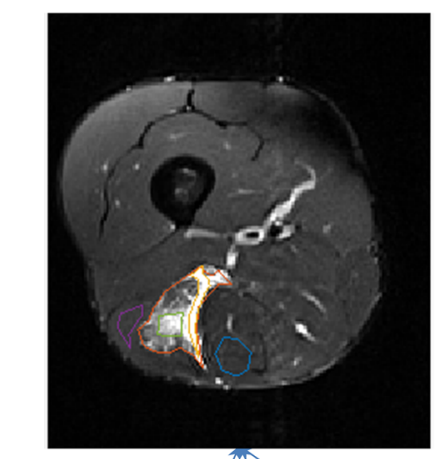

rigid

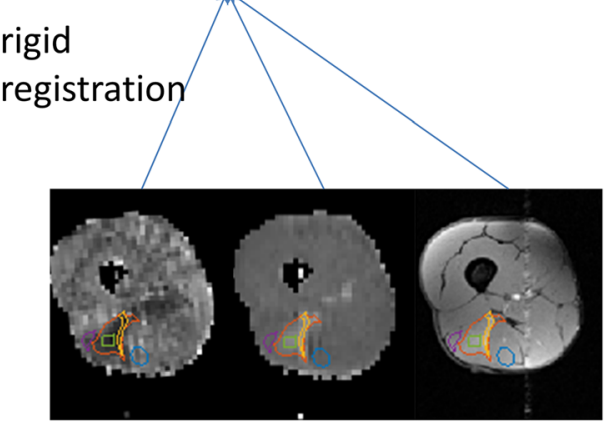

FA MD

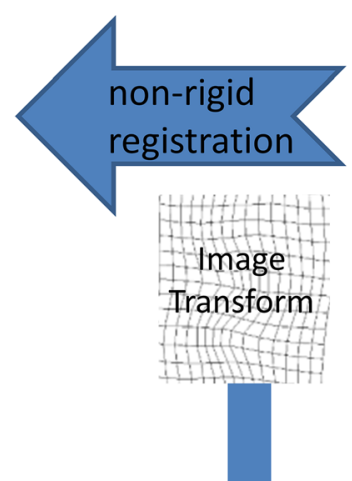

Visit 2

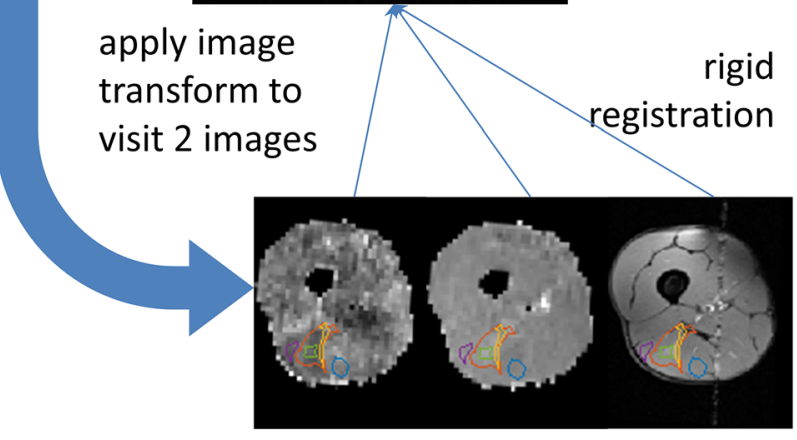

FA

MD

TSE

then applied to all visit 2 image sets. Subsequently, to correct for withinscan motion, all image datasets in each visit were aligned to the STIR image for that visit using rigid registration

scan (mean age 25 years, range 19 to 34 years ( 8 did not want to take the time to return for a second scan)). Eight tears were situated in the biceps femoris (6 right side, 2 left side), two in the semitendinosus (both left side), 2 in the soleus ( 1 each side) and 1 in the gastrocnemius (right side). Eleven tears were partial thickness injuries (BAMIC 1-3, modified Peetrons 1-2), and two were complete muscle tears (BAMIC 4, modified Peetrons 3). The mean return to play time was 31 days (range, 17 to 56 days). Players were followed up for 1 year during which none of the recruited athletes had a re-tear at the site of the study injury.

\section{Registration}

Radiologists visually confirmed that the image registration was accurate in all cases. Seven of the visit 2 haematoma ROIs were excluded from the analysis because the haematoma had resolved, leaving the haematoma ROI in fascial or subcutaneous fat (fat fraction > 20\%).

\section{Results}

\section{Participants}

Twenty-one male athletes with acute muscle tears were recruited into the study, of which thirteen returned for a second

\section{Longitudinal study}

There was a significant change in BAMIC score between visits $(Z=-2.088, p=0.037)$. The median BAMIC score was $2 b$ at visit 1 and $1 b$ at visit 2 . In $5 / 13$ participants, the 
BAMIC score did not reduce between visits. The mean differences in quantitative MRI parameters in these cases were T2, $14.2(95 \% \mathrm{CI},-2.1,30.4) \mathrm{ms}$; MD, $0.20(-0.41,0.80) \times$ $10^{-3} \mathrm{~mm}^{2} \mathrm{~s}^{-1}$; and FA, $-0.08(-0.15,-0.01)$ for the tear site ROI.

There was a significant change in modified Peetrons $(Z=-2.530, p=0.011)$ between visits. Median Peetrons score stayed at 2 between visits. In 6/13 participants, the Peetrons score did not reduce between visits. The mean differences in quantitative MRI parameters in these cases were T2, 13.9 (95\% CI, 3.7, 24.2) $\mathrm{ms}$; MD, $0.18(-0.11,0.47) \times 10^{-3} \mathrm{~mm}^{2} \mathrm{~s}^{-1}$; and FA, $-0.07(-0.03,-0.11)$.

\section{Visit 1 ROIs}

Considering the ROIs drawn on the initial (visit 1) images, incorporating the whole of the initial tear, T2 values were significantly lower at visit 2 in the tear site, haematoma and oedema ROIs (Fig. 2, Table 2). MD, $\lambda_{2}$ and $\lambda_{3}$ were significantly reduced after healing in the tear site and oedema, and FA was increased. There was no significant change in $\lambda_{1}$ and there were no significant longitudinal differences in normal muscle for any of the measures.

\section{Visit 2 ROIs}

Considering the ROIs drawn on the visit 2 images within the tear site, there was still a significant reduction in T2, MD and $\lambda_{3}$, and an increase in FA, with healing but differences in $\lambda_{2}$ were no longer significant (Fig. 3, Table 3).

\section{Return to play time prediction study}

BAMIC and modified Peetrons scores correlated with T2, MD, FA, $\lambda_{2}$ and $\lambda_{3}$ values in the tear site and oedema ROIs (Fig. 4, Table 4). However, in the haematoma ROI, none of the measures correlated with radiologist's scores.

BAMIC scores showed a good correlation with return to play time (Fig. 5, $R_{\mathrm{s}}=0.64 ; p=0.02$ ). Modified Peetrons score did not correlate with return to play time $\left(R_{\mathrm{S}}=0.40\right.$; $p=0.18)$. None of the quantitative MRI measures correlated well with return to play time for any of the ROIs assessed (Fig. 6, Table 5).

\section{Discussion}

This is the first study to use a longitudinal study design to assess quantitative measurements of $\mathrm{T} 2$ and diffusion in
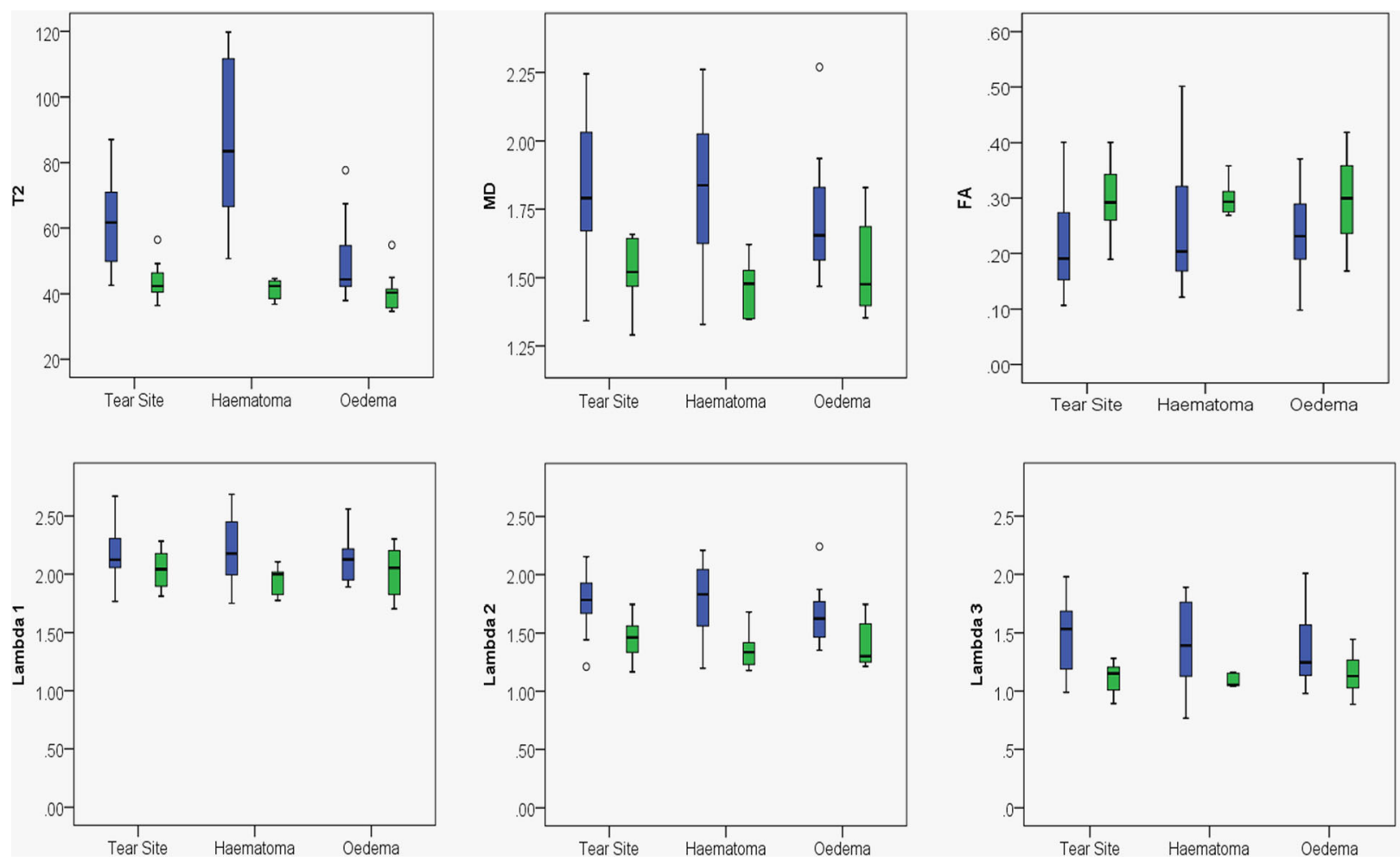

Fig. 2 Boxplots for quantitative MR parameters obtained from ROIs drawn on visit 1 and propagated to visit 2 . Measurements show tissue changes and the effect of the tear shrinking. Values for T2, MD and FA and eigenvalues in tear site, haematoma and oedema for both visits are presented 
Table 2 Quantitative MR parameters obtained from ROIs drawn on visit 1 and propagated to visit 2. Measurements show tissue changes and the effect of shrinking tear size. Values for T2, $\mathrm{MD}$ and FA and eigenvalues in tear site, haematoma and oedema are presented. Mean values for both visits and the difference between them are presented as mean (confidence interval); $p$ value

\begin{tabular}{|c|c|c|c|}
\hline ROI measurement & Visit 1 mean $(\mathrm{CI})$ & Visit 2 mean $(\mathrm{CI})$ & Difference mean $(\mathrm{CI}) ; p$ value \\
\hline \multicolumn{4}{|l|}{ Tear site } \\
\hline $\mathrm{T} 2(\mathrm{~ms})$ & $63.4(54.2,72.7)$ & $43.5(39.9,47.1)$ & $19.9(11.5,28.3) ; p<0.001$ \\
\hline $\mathrm{MD}\left(\times 10^{-3} \mathrm{~mm}^{2} \mathrm{~s}^{-1}\right)$ & $1.86(1.67,2.04)$ & $1.53(1.45,1.62)$ & $0.32(0.09,0.55) ; p=0.001$ \\
\hline FA & $0.19(0.15,0.23)$ & $0.30(0.26,0.34)$ & $0.11(0.17,0.06) ; p=0.001$ \\
\hline$\lambda_{1}\left(\times 10^{-3} \mathrm{~mm}^{2} \mathrm{~s}^{-1}\right)$ & $2.21(2.02,2.04)$ & $2.03(1.92,2.14)$ & $0.18(-0.05,0.41) ; p=0.12$ \\
\hline$\lambda_{2}\left(\times 10^{-3} \mathrm{~mm}^{2} \mathrm{~s}^{-1}\right)$ & $1.80(1.61,1.99)$ & $1.45(1.34,1.56)$ & $0.35(0.10,0.59) ; p=0.01$ \\
\hline$\lambda_{3}\left(\times 10^{-3} \mathrm{~mm}^{2} \mathrm{~s}^{-1}\right)$ & $1.56(1.35,1.77)$ & $1.11(1.02,1.20)$ & $0.45(0.21,0.69) ; p=0.002$ \\
\hline \multicolumn{4}{|l|}{ Haematoma } \\
\hline $\mathrm{T} 2(\mathrm{~ms})$ & $88.7(63.1,114.4)$ & $41.3(38.3,44.3)$ & $47.4(21.8,73.1) ; p=0.004$ \\
\hline $\mathrm{MD}\left(\times 10^{-3} \mathrm{~mm}^{2} \mathrm{~s}^{-1}\right)$ & $1.81(1.45,2.18)$ & $1.47(1.36,1.58)$ & $0.35(-0.04,0.73) ; p=0.07$ \\
\hline FA & $0.21(0.11,0.32)$ & $0.30(0.27,0.33)$ & $0.09(0.02,0.19) ; p=0.09$ \\
\hline$\lambda_{1}\left(\times 10^{-3} \mathrm{~mm}^{2} \mathrm{~s}^{-1}\right)$ & $2.18(1.82,2.53)$ & $1.95(1.82,2.09)$ & $0.22(-0.12,0.57) ; p=0.16$ \\
\hline$\lambda_{2}\left(\times 10^{-3} \mathrm{~mm}^{2} \mathrm{~s}^{-1}\right)$ & $1.76(1.36,2.15)$ & $1.36(1.17,1.55)$ & $0.39(-0.05,0.84) ; p=0.07$ \\
\hline$\lambda_{3}\left(\times 10^{-3} \mathrm{~mm}^{2} \mathrm{~s}^{-1}\right)$ & $1.47(1.02,1.92)$ & $1.09(1.03,1.14)$ & $0.38(-009,0.85) ; p=0.08$ \\
\hline \multicolumn{4}{|l|}{ Oedema } \\
\hline $\mathrm{T} 2(\mathrm{~ms})$ & $49.1(42.0,56.1)$ & $40.4(42.0,56.1)$ & $8.7(2.03,15.4) ; p=0.03$ \\
\hline $\mathrm{MD}\left(\times 10^{-3} \mathrm{~mm}^{2} \mathrm{~s}^{-1}\right)$ & $1.71(1.57,1.86)$ & $1.53(1.42,1.63)$ & $0.18(0.03,0.34) ; p=0.025$ \\
\hline FA & $0.22(0.18,0.27)$ & $0.29(0.24,0.34)$ & $0.07(0.00,0.13) ; p=0.05$ \\
\hline$\lambda_{1}\left(\times 10^{-3} \mathrm{~mm}^{2} \mathrm{~s}^{-1}\right)$ & $2.12(1.99,2.24)$ & $2.02(1.90,2.14)$ & $0.10(-0.05,0.25) ; p=0.18$ \\
\hline$\lambda_{2}\left(\times 10^{-3} \mathrm{~mm}^{2} \mathrm{~s}^{-1}\right)$ & $1.64(1.48,1.81)$ & $1.41(1.28,1.54)$ & $0.24(0.04,0.43) ; p=0.01$ \\
\hline$\lambda_{3}\left(\times 10^{-3} \mathrm{~mm}^{2} \mathrm{~s}^{-1}\right)$ & $1.38(1.20,1.57)$ & $1.16(1.04,1.27)$ & $0.23(0.04,0.42) ; p=0.02$ \\
\hline
\end{tabular}
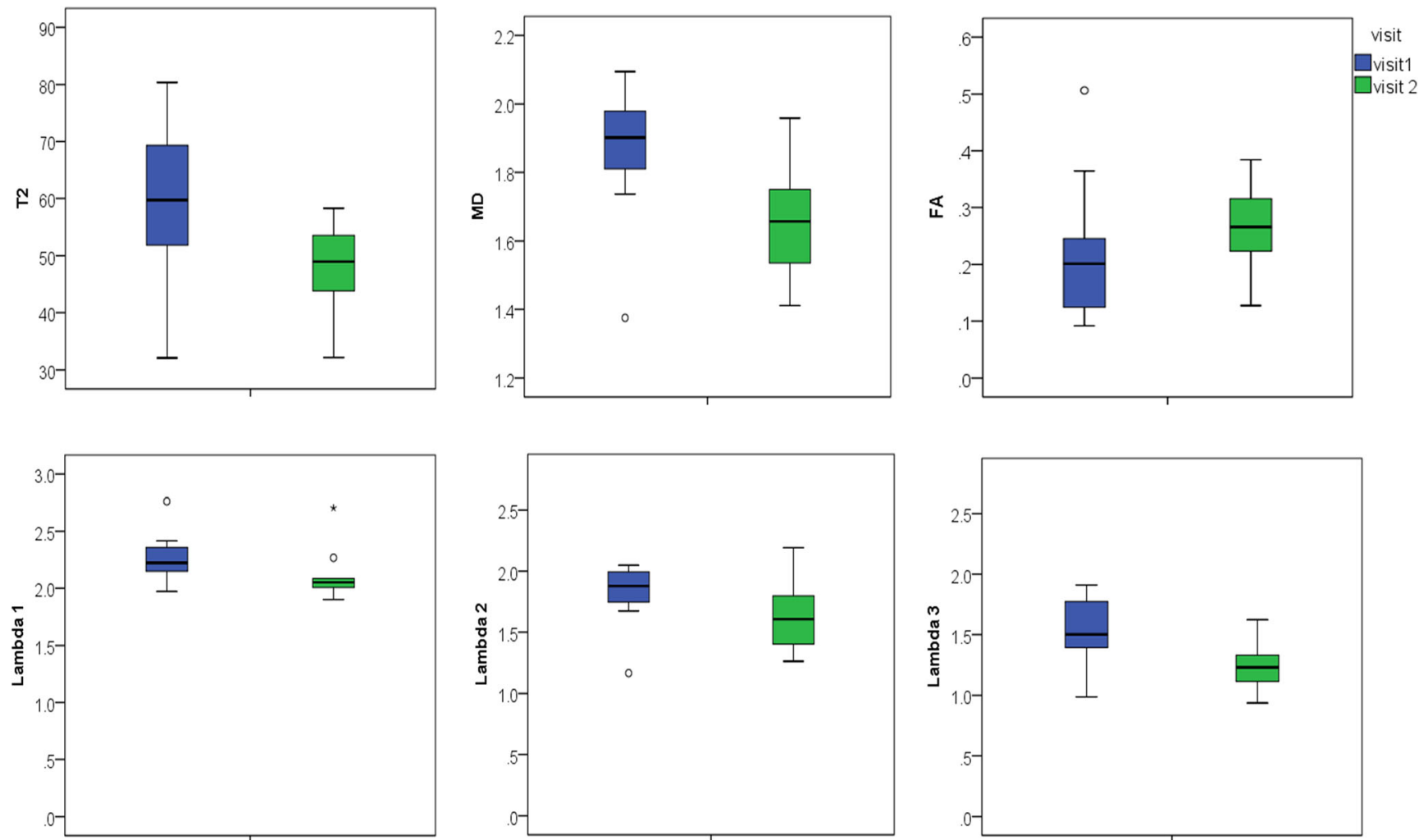

Fig. 3 Boxplots for quantitative MR parameters obtained from ROIs drawn on visit 2 and propagated to visit 1. Measurements show tissue changes within the tear site only. Values for T2, MD and FA and eigenvalues in the tear site are presented 
Table 3 Quantitative MR parameters obtained from ROIs drawn on visit 2 and propagated to visit 1 . Measurements show tissue changes within the tear site only. Mean values for T2, MD and FA and eigenvalues for both visits and the difference between them are presented as mean (confidence interval); $p$ value

\begin{tabular}{lccl}
\hline Measurement & Visit 1 mean $(\mathrm{CI})$ & Visit 2 mean $(\mathrm{CI})$ & Difference mean $(\mathrm{CI}) ; p$ value \\
\hline $\mathrm{T} 2(\mathrm{~ms})$ & $60.04(49.73,70.35)$ & $47.34(41.09,53.59)$ & $13.12(4.82,21.42) ; p=0.01$ \\
$\mathrm{MD}\left(\times 10^{-3} \mathrm{~mm}^{2} \mathrm{~s}^{-1}\right)$ & $1.86(1.72,2.01)$ & $1.65(1.52,1.77)$ & $0.22(0.04,0.39) ; p=0.02$ \\
$\mathrm{FA}$ & $0.19(0.13,0.25)$ & $0.26(0.21,0.32)$ & $0.07(0.01,0.14) ; p=0.03$ \\
$\lambda_{1}\left(\times 10^{-3} \mathrm{~mm}^{2} \mathrm{~s}^{-1}\right)$ & $2.23(2.13,2.32)$ & $2.11(1.94,2.28)$ & $0.12(-0.08,0.31) ; p=0.09$ \\
$\lambda_{2}\left(\times 10^{-3} \mathrm{~mm}^{2} \mathrm{~s}^{-1}\right)$ & $1.81(1.62,2.00)$ & $1.63(1.44,1.83)$ & $0.18(-0.08,0.44) ; p=0.16$ \\
$\lambda_{3}\left(\times 10^{-3} \mathrm{~mm}^{2} \mathrm{~s}^{-1}\right)$ & $1.55(1.36,1.74)$ & $1.23(1.09,1.37)$ & $0.32(0.14,0.50) ; p=003$ \\
\hline
\end{tabular}

muscle tear. We have shown that T2 and DTI measurements are able to detect changes in muscle due to healing after muscle tear. Measurements showed differences when muscle tear size changes were included in the ROI (visit 1 ROI comparison; Table 2, Fig. 2) and when only changes within the tear site itself were considered (visit 2 ROI comparison; Table 3, Fig. 3). Although radiologist's BAMIC scores correlated with return to play times, quantitative MRI values did not. Our results suggest that single-point ROI-based quantitative T2 and DTI measurements are not adequate predictors of return to play time. We would recommend radiologist's BAMIC scores as having the most potential to predict return to play times post muscle tear in athletes.
The obtained values for $\mathrm{T} 2$ and MD agreed well with previous measurements in healthy muscle at $3 \mathrm{~T}[25,29-31]$. The differences seen using the visit 1 ROIs represent changes within the tear site itself and due to tear size reduction. These visit 1 measurements are of clinical importance because they are the only measurements that are available to a radiologist immediately after muscle tear. The observed reduction in $\mathrm{T} 2$ values and mean diffusivity is consistent with a reduction in fluid in response due to decreasing levels of oedema. The reduction in mean diffusivity is also consistent with fluid changes. The corresponding increase in fractional anisotropy could show restored fibre microstructure. As torn fibres are repaired, the inhomogeneity in fibre direction should decrease, increasing the FA. This is corroborated to some extent by the reduction in $\lambda_{2}$ and $\lambda_{3}$, which is consistent with reordering of
Fig. 4 Scatter plots showing correlations between BAMIC scores and T2 (a), FA (b) and MD (c) in the tear site ROI a)

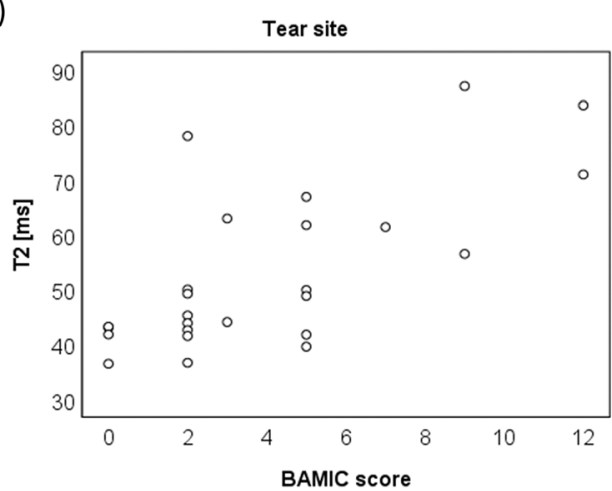

c)

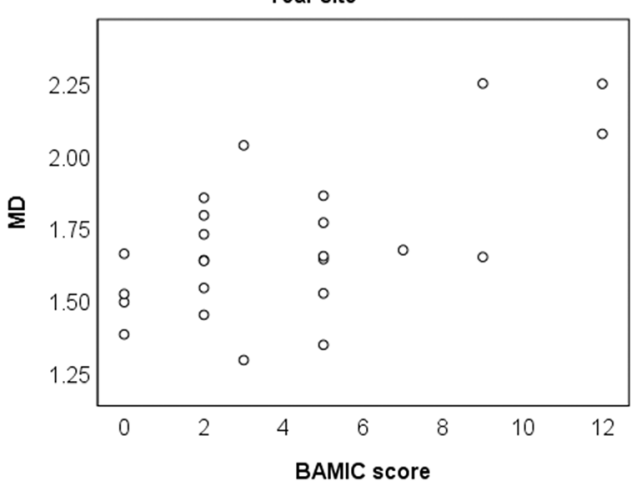

b)

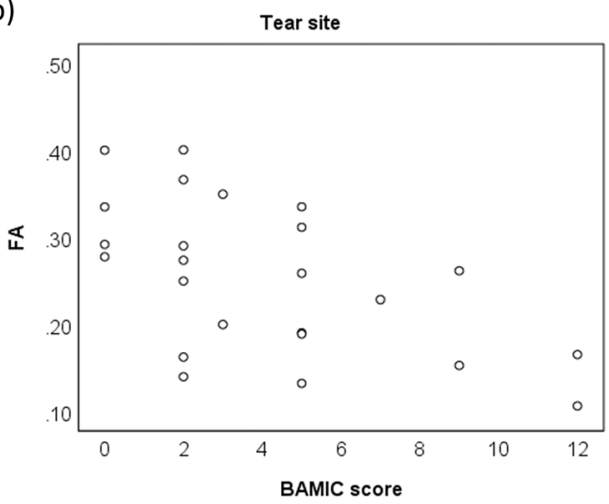


Table 4 Spearman's $R$ values and $p$ values for correlations between BAMIC and modified Peetrons scores compared with $\mathrm{T} 2, \mathrm{MD}$ and FA and eigenvalues in tear site, haematoma and oedema ROIs

\begin{tabular}{lllll}
\hline Measurement & Score & Tear site & Haematoma & Oedema \\
\hline T2 (ms) & BAMIC & $R=0.62 ; p<0.01$ & $R=0.36 ; p=0.18$ & $R=0.48 ; p=0.01$ \\
& Peetrons & $R=0.59 ; p=0.01$ & $R=0.51 ; p=-0.05$ & $R=0.68 ; p<0.01$ \\
MD $\left(\times 10^{-3} \mathrm{~mm}^{2} \mathrm{~s}^{-1}\right)$ & BAMIC & $R=0.49 ; p=0.01$ & $R=0.27 ; p=0.35$ & $R=0.52 ; p=0.01$ \\
& Peetrons & $R=0.51 ; p=0.01$ & $R=0.56 ; p=0.04$ & $R=0.57 ; p=0.01$ \\
FA & BAMIC & $R=-0.53 ; p<0.01$ & $R=-0.32 ; p=0.27$ & $R=-0.41 ; p=0.04$ \\
& Peetrons & $R=-0.51 ; p=0.01$ & $R=-0.19 ; p=0.52$ & $R=-0.41 ; p=0.04$ \\
$\lambda_{1}\left(\times 10^{-3} \mathrm{~mm}^{2} \mathrm{~s}^{-1}\right)$ & BAMIC & $R=0.30 p=0.15$ & $R=0.11 ; p=0.70$ & $R=0.38 ; p=0.06$ \\
& Peetrons & $R=0.29 ; p=0.16$ & $R=0.56 ; p=0.04$ & $R=0.36 ; p=0.08$ \\
$\lambda_{2}\left(\times 10^{-3} \mathrm{~mm}^{2} \mathrm{~s}^{-1}\right)$ & BAMIC & $R=0.56 ; p=<0.01$ & $R=0.28 ; p=0.33$ & $R=0.61 ; p=0.001$ \\
& Peetrons & $R=0.56 ; p<0.01$ & $R=0.52 ; p=0.06$ & $R=0.56 ; p<0.01$ \\
$\lambda_{3}\left(\times 10^{-3} \mathrm{~mm}^{2} \mathrm{~s}^{-1}\right)$ & BAMIC & $R=0.61 ; p<0.01$ & $R=0.41 ; p=0.14$ & $R=0.54 ; p<0.01$ \\
& Peetrons & $R=0.70 ; p<0.01$ & $R=0.56 ; p=0.04$ & $R=0.48 ; p=0.02$ \\
\hline
\end{tabular}

the fibres due to healing but could also be affected by fluid reduction.

Analysis of the visit 2 ROIs allowed a separate analysis of changes within the tear site, excluding the effects of tear shrinking. Our results showed that T2 and MD measurements can detect reductions in fluid content within the tear site itself and not just due to reduction in the tear volume. Here, the increase in FA between visits could be due to fibre reordering within the tear.

Although BAMIC scores correlated well with return to play time, the modified Peetrons scale had an inadequate value range to be able to show a strong correlation, with

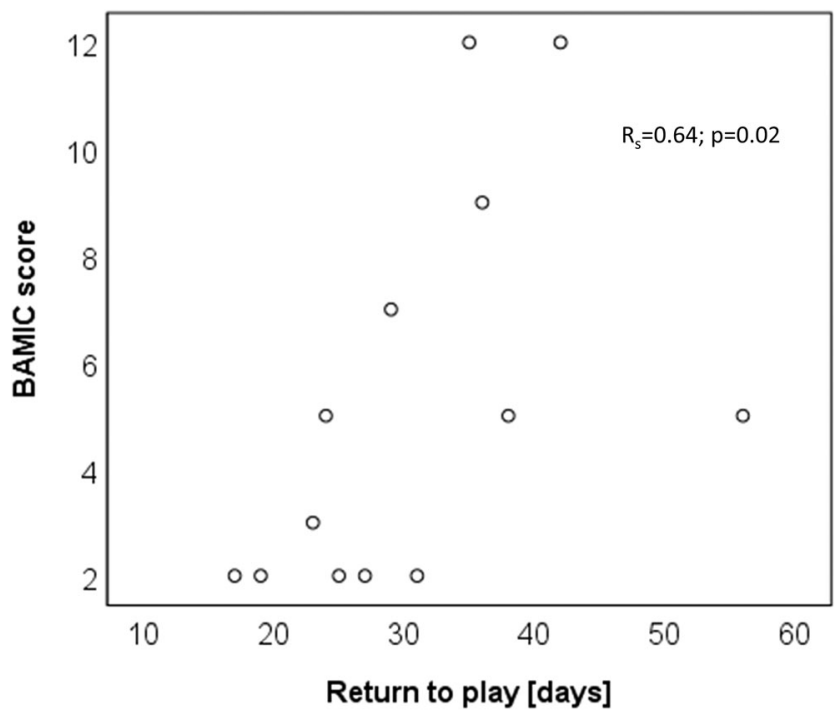

Fig. 5 Correlation between radiologist's BAMIC score and return to play time
$11 / 13$ cases having a score of 2 at visit 1 . This also explains why more Peetrons scores remained unchanged between visits than BAMIC. Given that BAMIC scores correlated with return to play time (supporting previous studies [2]) and with quantitative MRI, it is disappointing that quantitative MRI measurements did not independently correlate with return to play time. This is likely due to the limited scope of a single ROI-based measurement within the tear site compared with the radiologist's score, which takes into account the tear size relative to the muscle belly, signal changes, position, and muscle retraction. Figure $6 a$ shows a possible relationship, but the correlation is poor due to two outliers, with return to play times of 17 and 56 days. Excluding these outliers gives a correlation $(R=0.66 ; p=0.02)$. On investigation, the 56-day point was also an outlier in the radiologist's score plot (BAMIC of 2b) and the ROI placement seemed sensible. However, the 17-day point was not an outlier on BAMIC score $($ BAMIC $=1 \mathrm{~b})$ and had an exceptionally small tear site. The unusually high T2 value could be due to misplacement of the ROI and illustrates the potential limitations of ROI-based quantitative MRI as a tool in the muscle. Nevertheless, even when this point was excluded, the correlation between $\mathrm{T} 2$ and return to play time in the tear site remained low $(R=0.31 ; p=0.33)$, so our conclusion remains that quantitative T2 and DTI values are not good predictors of return to play time.

There were limitations to our study. The sample size was small and the patient group was relatively heterogeneous. We did not correct for muscle changes due to age in our study. The relatively broad (19-35 years) age 
Fig. 6 Scatter plots between T2 and return to play times in the tear site (a), haematoma (b) and oedema $(\mathbf{c})$

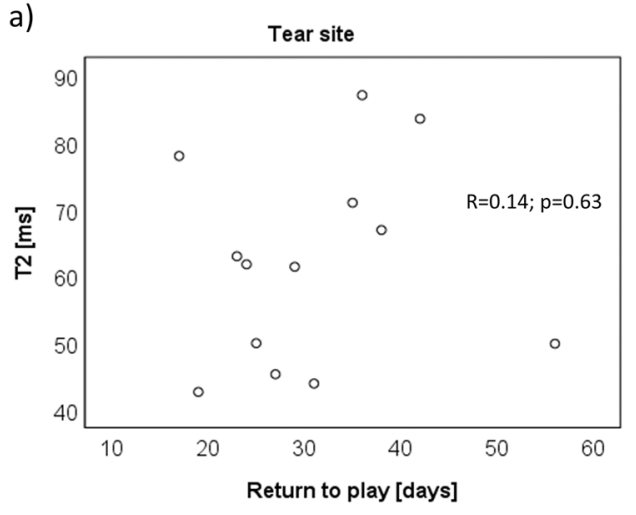

b)

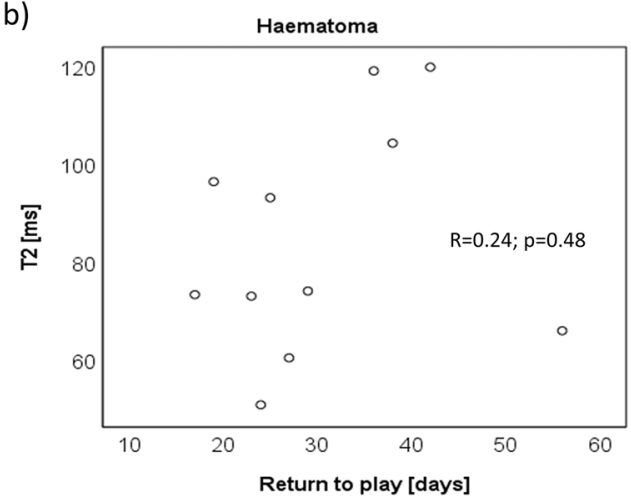

c)

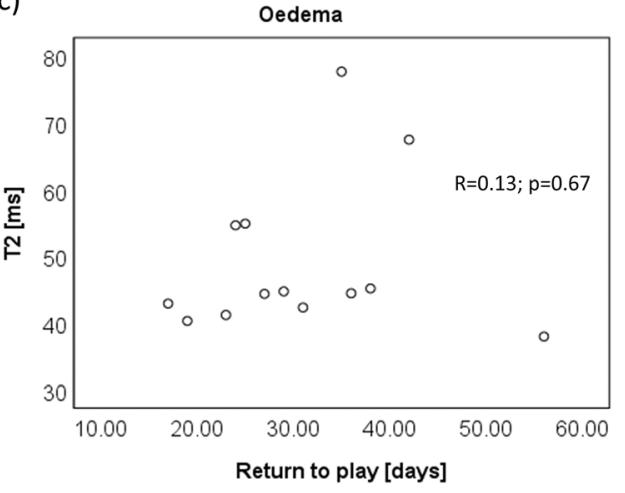

range of our participants might have decreased the ability to predict return to play time. There was a long delay (4 years) between acquisition of the data and submission of the paper for publication due to a number of factors including slow responses from the sports club over the 1-year follow-up data, the time taken to develop the post-processing software and staff changes at our institution. Imaging was performed within a week of injury, but a more stringent time window, such as 24 48 suggested by Ekstrand et al [6], may have given the MRI measurements more predictive power. A 3D registration approach might have reduced variation in slice position between visits. Although widely used, the use of a multi-echo sequence with a mono-exponential fit is susceptible to errors [20,32]. Scoring was reported by only one radiologist and this could have been improved with a consensus reporting approach. Although blinded to BAMIC scores and tear size measurements, medical teams did receive a clinical report based on the first scan which could have biased return to play time estimates. Although it is currently the clinical reference measure, return to play time is a subjective measure and is therefore limited as a reference standard for degree of healing.
Table 5 Pearson's $R$ values and $p$ values for correlations between return to play time and visit 1 values for $\mathrm{T} 2, \mathrm{MD}$ and $\mathrm{FA}$ and eigenvalues in tear site, haematoma and oedema

\begin{tabular}{llll}
\hline Measurement & Tear site & Haematoma & Oedema \\
\hline $\mathrm{T} 2(\mathrm{~ms})$ & $R=0.14 ; p=0.64$ & $R=0.24 ; p=0.48$ & $R=0.13 ; p=0.67$ \\
$\mathrm{MD}\left(\times 10^{-3} \mathrm{~mm}^{2} \mathrm{~s}^{-1}\right)$ & $R=0.20 ; p=0.51$ & $R=0.19 ; p=0.58$ & $R=0.21 ; p=0.49$ \\
$\mathrm{FA}$ & $R=-0.27 ; p=0.38$ & $R=-0.28 ; p=0.41$ & $R=-0.42 ; p=0.15$ \\
$\lambda_{1}\left(\times 10^{-3} \mathrm{~mm}^{2} \mathrm{~s}^{-1}\right)$ & $R=0.11 ; p=0.71$ & $R=-0.04 ; p=0.92$ & $R=0.02 ; p=0.95$ \\
$\lambda_{2}\left(\times 10^{-3} \mathrm{~mm}^{2} \mathrm{~s}^{-1}\right)$ & $R=0.09 ; p=0.77$ & $R=0.15 ; p=0.67$ & $R=0.14 ; p=0.64$ \\
$\lambda_{3}\left(\times 10^{-3} \mathrm{~mm}^{2} \mathrm{~s}^{-1}\right)$ & $R=0.33 ; p=0.28$ & $R=0.29 ; p=0.39$ & $R=0.35 ; p=0.24$ \\
\hline
\end{tabular}




\section{Conclusions}

T2 and DTI measurements in muscle can detect changes due to healing following muscle tear. T2 and MD values decrease, and FA increases, as the muscle heals. These trends are observed within the tear site itself and when changes due to shrinking of the tear volume are included in the ROI. In this study, radiologist's BAMIC scores correlated with return to play times specified by the sports medicine team; however, modified Peetrons scores and quantitative MRI values did not. Our results suggest that single measurement, ROI-based quantitative T2 and DTI measurements are inferior predictors of return to play time compared with visual scoring.

Acknowledgements JDB is funded by a National Institute for Health Research (NIHR) (and Health Education England) Clinical Lectureship. AJG was funded by the NIHR. The research is supported by the NIHR infrastructure at Leeds. The views expressed are those of the author(s) and not necessarily those of the NHS, the NIHR or the Department of Health. We are grateful to Dr. Elizabeth Hensor for statistical advice.

Funding The authors state that this work has not received any funding.

\section{Compliance with ethical standards}

Guarantor The scientific guarantor of this publication is Dr. John D Biglands.

Conflict of interest Thorsten Feiweier is an employee of Siemens Healthcare $\mathrm{GmbH}$, owns stocks of Siemens (Healthineers) AG and holds patents filed by Siemens.

Statistics and biometry Dr. Elizabeth Hensor kindly provided statistical advice for this manuscript.

Informed consent Written informed consent was obtained from all subjects (patients) in this study.

Ethical approval Institutional Review Board approval was obtained.

\author{
Methodology \\ - prospective \\ - observational \\ - performed at one institution
}

Open Access This article is licensed under a Creative Commons Attribution 4.0 International License, which permits use, sharing, adaptation, distribution and reproduction in any medium or format, as long as you give appropriate credit to the original author(s) and the source, provide a link to the Creative Commons licence, and indicate if changes were made. The images or other third party material in this article are included in the article's Creative Commons licence, unless indicated otherwise in a credit line to the material. If material is not included in the article's Creative Commons licence and your intended use is not permitted by statutory regulation or exceeds the permitted use, you will need to obtain permission directly from the copyright holder. To view a copy of this licence, visit http://creativecommons.org/licenses/by/4.0/.

\section{References}

1. Lee JC, Mitchell AWM, Healy JC (2012) Imaging of muscle injury in the elite athlete. Br J Radiol 85:1173-1185. https://doi.org/10. $1259 / \mathrm{bjr} / 84622172$

2. Fournier-Farley C, Lamontagne M, Gendron P, Gagnon DH (2015) Determinants of return to play after the nonoperative management of hamstring injuries in athletes: a systematic review. Am J Sports Med 44:2166-2172. https://doi.org/10.1177/0363546515617472

3. Connell D, Schneider-Kolsky M, Hoving J et al (2004) Longitudinal study comparing sonographic and MRI assessments of acute and healing hamstring injuries. AJR Am J Roentgenol 183: 975-984. https://doi.org/10.2214/ajr.183.4.1830975

4. Slavotinek JP, Verrall GM, Fon GT (2002) Hamstring injury in athletes: using MR imaging measurements to compare extent of muscle injury with amount of time lost from competition. AJR Am J Roentgenol 179:1621-1628. https://doi.org/10.2214/ajr.179. 6.1791621

5. Reurink G, Brilman EG, de Vos RJ et al (2014) Magnetic resonance imaging in acute hamstring injury: can we provide a return to play prognosis? Sports Med 45:133-146. https://doi.org/10.1007/ s40279-014-0243-1

6. Ekstrand J, Healy JC, Waldén M, Lee JC, English B, Hägglund M (2012) Hamstring muscle injuries in professional football: the correlation of MRI findings with return to play. Br J Sports Med 46: 112-117. https://doi.org/10.1136/bjsports-2011-090155

7. Peetrons P (2002) Ultrasound of muscles. Eur Radiol 12:35-43. https://doi.org/10.1007/s00330-001-1164-6

8. Patel A, Chakraverty J, Pollock N, Chakraverty R, Suokas AK, James SL (2015) British athletics muscle injury classification: a reliability study for a new grading system. Clin Radiol 70:1414 1420. https://doi.org/10.1016/j.crad.2015.08.009

9. Pollock N, James SLJ, Lee JC, Chakraverty R (2014) British athletics muscle injury classification: a new grading system. Br J Sports Med 48:1347-1351. https://doi.org/10.1136/bjsports-2013093302

10. Rushton A, Khurniawan KA, James S, Botchu R, Shamji R (2019) Return to play and recurrence rate following hamstring injury in elite football: use of the British athletics muscle injury classification. Physiotherapy 105:e45. https://doi.org/10.1016/j.physio.2018. 11.293

11. Malliaropoulos N, Isinkaye T, Tsitas K, Maffulli N (2011) Reinjury after acute posterior thigh muscle injuries in elite track and field athletes. Am J Sports Med 39:304-310. https://doi.org/10.1177/ 0363546510382857

12. Kumaravel M, Bawa P, Murai N (2018) Magnetic resonance imaging of muscle injury in elite American football players: predictors for return to play and performance. Eur J Radiol 108:155-164. https://doi.org/10.1016/j.ejrad.2018.09.028

13. Jacobsen P, Witvrouw E, Muxart P, Tol JL, Whiteley R (2016) A combination of initial and follow-up physiotherapist examination predicts physician-determined time to return to play after hamstring injury, with no added value of MRI. Br J Sports Med 50:431-439. https://doi.org/10.1136/bjsports-2015-095073

14. Hamilton B, Wangensteen A, Whiteley R et al (2018) Cohen's MRI scoring system has limited value in predicting return to play. Knee Surg Sports Traumatol Arthrosc 26:1288-1294. https://doi.org/10. 1007/s00167-016-4403-8

15. Ford GM, Genuario J, Kinkartz J, Githens T, Noonan T (2016) Return-to-play outcomes in professional baseball players after medial ulnar collateral ligament injuries. Am J Sports Med 44:723728. https://doi.org/10.1177/0363546515621756

16. Nealon AR, Docking SI, Lucas PE, Connell DA, Koh ES, Cook JL (2019) MRI findings are associated with time to return to play in first class cricket fast bowlers with side strain in Australia and 
England. J Sci Med Sport 22:992-996. https://doi.org/10.1016/j. jsams.2019.05.020

17. Ran J, Ji S, Morelli JN, Wua G, Lia X (2018) T2 mapping in dermatomyositis/polymyositis and correlation with clinical parameters. Clin Radiol 73:1057.e13-1057.e18. https://doi.org/10.1016/j. crad.2018.07.106

18. Maillard SM, Jones R, Owens C et al (2004) Quantitative assessment of MRI T2 relaxation time of thigh muscles in juvenile dermatomyositis. Rheumatology (Oxford) 43:603-608. https://doi. org/10.1093/rheumatology/keh130

19. Ababneh ZQ, Ababneh R, Maier SE et al (2008) On the correlation between $\mathrm{T} 2$ and tissue diffusion coefficients in exercised muscle: quantitative measurements at $3 \mathrm{~T}$ within the tibialis anterior. MAGMA 21:273-278. https://doi.org/10.1007/s10334-008-0120-8

20. Ploutz-Snyder LL, Nyren S, Cooper TG, Potchen EJ, Meyer RA (1997) Different effects of exercise and edema on T2 relaxation in skeletal muscle. Magn Reson Med 37:676-682. https://doi.org/10. 1002/mrm.1910370509

21. Heemskerk AM, Strijkers GJ, Drost MR, van Bochove GS, Nicolay K (2007) Skeletal muscle degeneration and regeneration after femoral artery ligation in mice: monitoring with diffusion MR imaging. Radiology 243:413-421. https://doi.org/10.1148/radiol. 2432060491

22. Zaraiskaya T, Kumbhare D, Noseworthy MD (2006) Diffusion tensor imaging in evaluation of human skeletal muscle injury. J Magn Reson Imaging 24:402-408. https://doi.org/10.1002/jmri. 20651

23. Giraudo C, Motyka S, Weber M et al (2018) Normalized STEAMbased diffusion tensor imaging provides a robust assessment of muscle tears in football players : preliminary results of a new approach to evaluate muscle injuries. Eur Radiol 28:2882-2889. https://doi.org/10.1007/s00330-017-5218-9

24. Lancaster G (2004) Design and analysis of pilot studies: recommendations for good practice. J Eval Clin Pract 10:307-312. https://doi. $\operatorname{org} / 10.1111 / \mathrm{j} .2002 .384 . d o c . x$
25. Farrow M, Grainger AJ, Tan AL et al (2019) Normal values and test-retest variability of stimulated-echo diffusion tensor imaging and fat fraction measurements in the muscle. Br J Radiol 92. https:// doi.org/10.1259/bjr.20190143

26. Ibáñez L, Schroeder W, Ng L, Cates J (2005) The ITK software guide, second. Kitware, Inc., New York

27. Mattes D, Haynor DR, Vesselle H, Lewellyn TK, Eubank W (2001) Nonrigid multimodality image registration. In: Sonka M, Hanson KM (eds) SPIE medical imaging. SPIE, pp 1609-1620

28. Milford D, Rosbach N, Bendszus M, Heiland S (2015) Monoexponential fitting in T2-relaxometry: relevance of offset and first echo. PLoS One 10:1-13. https://doi.org/10.1371/journal.pone. 0145255

29. Li K, Dortch RD, Welch EB et al (2014) Multi-parametric MRI characterization of healthy human thigh muscles at $3.0 \mathrm{~T}$ - relaxation, magnetization transfer, fat/water, and diffusion tensor imaging. NMR Biomed 27:1070-1084. https://doi.org/10.1002/nbm. 3159

30. Morrow JM, Sinclair CDJ, Fischmann A et al (2014) Reproducibility, and age, body-weight and gender dependency of candidate skeletal muscle MRI outcome measures in healthy volunteers. Eur Radiol 24:1610-1620. https://doi.org/10.1007/ s00330-014-3145-6

31. Stanisz GJ, Odrobina EE, Pun J et al (2005) T1, T2 relaxation and magnetization transfer in tissue at 3T. Magn Reson Med 54:507512. https://doi.org/10.1002/mrm.20605

32. Pai A, Li X, Majumdar S (2008) A comparative study at 3 Tesla of sequence dependence of T 2 quantitation in the knee. Magn Reson Imaging 26:1215-1220. https://doi.org/10.1016/j.mri.2008.02.017.A

Publisher's note Springer Nature remains neutral with regard to jurisdictional claims in published maps and institutional affiliations. 